\title{
A ATIVIDADE FILOSÓFICA EM ALGUNS PENSADORES ORIGINÁRIOS
}

\author{
Cezar Luís SEIBT \\ Campus Universitário de Cametá/UFPA \\ celuse@ufpa.br
}

\begin{abstract}
Resumo: O pensamento ocidental se enraíza na atividade reflexiva dos primeiros filósofos gregos. Eles são considerados pensadores originários, pois se ocuparam com questões que se tornaram os problemas fundamentais da filosofia posterior e cuja formulação acompanhou toda história do ocidente. $\mathrm{O}$ artigo pretende mostrar a grandeza desse pensamento originário e apontar para os conceitos importantes que surgem diante dos problemas enfrentados pela filosofia nas suas origens, em alguns dos pensadores originários.
\end{abstract}

Palavras-chave: Pensamento originário. Pré-socráticos. Filosofia. Pensamento grego.

\begin{abstract}
The occidental thought takes its roots in the reflexive activity of the first Greek philosophers. They are considered as originary thinkers, for they occupied themselves with questions that became the basic problems of the posterior philosophy and whose formularization followed all the history of the Western Hemisphere. The article intends to show the greatness of this originary thought and to point to the important concepts that arise in the face of the problems faced by the philosophy in its origins, in some of the originary thinkers.
\end{abstract}

Keywords: Originary thought. Pre-Socratics. Philosophy. Greek thought.

\section{Introdução}

O pensamento produzido pelos primeiros filósofos da Grécia já nasceu grande, contrariamente ao que se apregoou durante muito tempo, como diz Carneiro Leão (1990). Não se aceita mais a concepção de que a filosofia destes autores teria sido apenas uma etapa menos adiantada em direção a outra mais evoluída, aquela de Sócrates, Platão e Aristóteles. Essa depreciação é sugerida nas próprias expressões 'pré-socráticos', 'pré-platônicos' ou 'préaristotélicos'. Muitos autores, tais como Nietzsche e Heidegger, mostram que a filosofia desses três grandes não é simplesmente uma continuação, mas muito mais uma ruptura em relação à produção dos pensadores originários. Com eles acontece uma de-cisão histórica fundamental para a filosofia e para a história do ocidente.

De-cisão significa aqui a escolha de um determinado caminho possível, dentre muitos outros que são excluídos. Esta de-cisão, este caminho institui as dicotomias: se pronuncia pelo ser contra o nada, pela ausência contra a aparência, pelo bem contra o mal, pelo inteligível contra o sensível, pelo permanente contra o mutável, pelo verdadeiro contra o falso, pelo 
racional contra o animal, pelo necessário contra o contingente, pelo uno contra o múltiplo, pela sincronia contra a diacronia. É uma decisão que, no poder do seu jogo, de-cide pela filosofia contra o pensamento.

Esta de-cisão pela metafísica não é simplesmente passado, mas vigorou na história e vigora no presente. É, podemos assim dizer, a fonte de onde bebemos ainda hoje, a tradição que nos sustenta. Seu vigor histórico promoveu transformações, experiências, interpretações durante 25 séculos. Isso explica o ímpeto de diversos filósofos contemporâneos em buscarem, para trás desta grande de-cisão, a instituição de novas possibilidades para o pensamento, ou a própria libertação do pensamento para o pensar. A superação da metafísica supõe o re-encontro com as origens do pensamento, com o vigor originário que foi soterrado pela metafísica.

O que dissemos até agora introduz a idéia de que a partir de Sócrates nasceu a 'filosofia' que, em detrimento do 'pensamento' grego, nega um dos pólos contrastantes, transformando esses pólos dinâmicos - concebidos como duas faces de uma mesma realidade ou como aquilo que constitui a realidade, ao mesmo tempo una e múltipla - em dicotomias ou seja, em duas realidades independentes uma da outra. É essa filosofia que muitos autores atuais criticam a partir do pensado pelos pensadores originários da Grécia. E esse desvio do pensamento originário para um pensamento 'lógico', linear, dá origem à famosa metafísica, que será criticada e desconstruída por Heidegger e outros. É essa metafísica que fundamentará o Humanismo, o Iluminismo e a Ciência Moderna.

Mas o que nos interessa neste trabalho é apresentar muito brevemente aspectos do pensamento de alguns desses autores originários, representativos de momentos e posições diferentes, que caracterizam os movimentos da reflexão produzida nos inícios da filosofia na Grécia. Isso não é fácil, sobretudo pelo fato de estarmos habituados a pensar metafisicamente e estarmos a uma distância temporal significativa deles. Podemos estranhar o vigor e a ambigüidade daquele pensamento mesclado de luz e noite, vida e morte, mudança e imobilidade.

O pensamento desses filósofos é originário pelo que foram provocados a pensar em tudo que pensaram. Pensar é significar aquilo que nos pro-voca e, se retrai como mistério. Essa é a dinâmica do próprio pensamento. Aquilo que pro-voca, se retrai e assim nos arrasta. Somos assim, o significante do mistério. O homem é o pensador.

Realmente, assim como a realidade se dava e também se retraía para os pensadores 
originários, o seu próprio pensamento se nos dá, mas também se retrai na medida em que buscamos apreendê-lo e compreendê-lo. Mas, retraindo-se nos atrai a pensar.

O que se torna necessário retomar é o vigor originário do pensamento. O exercício de uma tal hermenêutica supõe um despojar-se de tudo o que se julga já saber sobre o pensamento dos primeiros pensadores gregos. Voltar-lhe à proveniência, com coragem de voltar às próprias raízes do pensar, de ser radical. Tudo isso é um resgate do pensamento sobre o ser nas diferenças do seu modo presente de ser. É um pensamento que se embrenha no mistério das dicotomias de ser e não-ser, de movimento e permanência, de uno e múltiplo, de aparência e verdade. Originário ontem, também pode provocar o originário hoje.

Entre os filósofos originários (pré-socráticos) há impulsos diferentes, que podem ser atribuídos a fatores tais como o período em que desenvolveram seu pensamento e também a região geográfica (com diferentes condições sociais e políticas) em que surgiram e se desenvolveram. De acordo com Kirk (1994, p. 222), podemos perceber isso no modo como os Milésios, os Jônios e os Eleáticos se diferenciam entre si. Os primeiros, descontentes com as explicações mitológicas e movidos pela curiosidade intelectual, buscaram uma explicação física sistemática dos fenômenos físicos. Já os pitagóricos (Jônios) eram movidos por um impulso de natureza religiosa (havia forte cultivo de mistérios e cultos em torno da morte e da adoração dos deuses do além no sul da Itália e Sicília), enquanto os eleáticos Parmênides e Zenão "propuseram paradoxos metafísicos que cortaram pela raiz a crença numa verdadeira existência do mundo natural" (KIRK, 1994, p. 222). Desse modo, podemos dizer que

Pitágoras é o arquétipo do filósofo considerado como o sábio que ensina
aos homens o significado da vida e da morte, e Parmênides, o fundador da
filosofia entendida, não como uma investigação de primeira ordem sobre a
natureza das coisas (presentemente, esfera de ação das ciências da
natureza), mas como estudo de segunda ordem do que quer dizer que algo
existe ou está em movimento ou é uma pluralidade (KIRK, 1994, p. 222).

Assim, a título de esclarecimento, mas sem com isso pretender esgotar o esforço empreendido nos inícios da filosofia na Grécia, podemos dizer que o filosofar oscila entre atribuir ao Ser ou ao Não-Ser o princípio explicativo da realidade. Alguns buscam o fundamento na permanência, no imutável, universal, num elemento unificador de tudo, que é o Ser. Outros, no entanto, consideram exatamente o móvel, o devir, o impermanente, a diversidade da natureza, ou seja, o não-Ser. Os filósofos posteriores, tal como é o caso de Platão e Aristóteles, irão se ocupar em grande parte com a resolução destes problemas formulados e trabalhados pelos seus predecessores. Como podemos chegar a um conhecimento seguro, universal, certo em meio a uma realidade em permanente mudança? $\mathrm{O}$ 
que podemos saber efetivamente daquilo que não permanece idêntico todo tempo? Em que âmbito encontrar um fundamento primeiro, um princípio explicativo, se é que há um tal princípio?

Vamos então, a partir de agora, apresentar alguns elementos que caracterizam esse pensamento originário em alguns autores, tais como Pitágoras, Parmênides, Empédocles e Górgias. Faremos uso dos fragmentos dos textos dos próprios pensadores em questão. Complementaremos com alguns outros intérpretes, na medida em que isso ajudar a esclarecer o pensamento.

\section{Pitágoras}

Segundo a tradição, Pitágoras é o autor da palavra "filosofia". Philos significa uma relação - buscar a metade que falta (a sophia) - uma paixão pela verdade, buscando compreensão e percepção das coisas que são. Além disso, é a virtude na ação, um tipo de vida que deverá favorecer a busca da verdade. Para ele o investigar, o estudar deve estar unido ao ser, viver, relacionar-se. Assim, a compreensão da verdade se dá na vida, com os outros, na prática da virtude. A prática da virtude nos faz seres humanos bons e o conhecimento das ciências conduz à virtude divina (inteligência). Para que isso aconteça é necessário desligar-se das paixões. Isso supõe desligar inteiramente o espírito do corpo, sem o que é impossível ver ou aprender algo. Para ele, somente o espírito vê e compreende, pois fora dele tudo no ser humano é surdo e cego. A filosofia pode assim alcançar a verdade que há nos seres.

O interesse de Pitágoras não está relacionado tão fortemente à natureza, mas sobretudo à alma. Sustentava que esta é imortal e que passa por uma seqüência de encarnações em diferentes criaturas, num movimento infinito e imutável.

Podemos dizer que ele é o primeiro pensador da música e da arte. Além disso, se para diversos pensadores anteriores e contemporâneos a ele o fundamento era o visível, agora, com ele, é o não-visível. O centro da vida é a morte. Com isso, ele se torna o primeiro pensador da psiché e da sobrevivência após a morte. Ele é, aliás, um pensador insistente da 'morte'. O centro é a morte e não o ser. Como veremos adiante, para Parmênides a morte é não-ser.

Pitágoras busca introduzir rigor naquilo que se afasta do rigor (a morte). Quer reduzir a diversidade à unidade. Isso deverá acontecer através da matemática. Ela é o rigor que deve ser introduzido naquilo que não permanece, que está em constante mudança. Por isso, o pensamento não pode ser elaborado na praça pública, pois ali é o lugar da paixão. Ele precisa 
de um lugar próprio, isolado da paixão, onde o rigor matemático possa ser introduzido.

É o número que rege o universo. Há uma música universal, uma harmonia que é calculável, que tem rigor, enquanto o mito, a paixão não tem essa calculabilidade. $\mathrm{O}$ que estava fora do cálculo passa a ser calculado por Pitágoras: aquilo que é e que devém, o passado e o futuro. Para ele, no centro tem que estar o fixo. No centro do que se move está o fixo, que é o número. Neste sentido, o número é a possibilidade de dominar a totalidade. Como diz Aristóteles dos pitagóricos, eles "foram os primeiros a se dedicar às matemáticas e desenvolvê-las. Formados nelas, pensaram que os princípios das matemáticas são os princípios de todos os entes". Em outro momento fala que "estes dizem que as próprias coisas são números" (ARISTÓTELES, 2002, 987b27e28). Isso de modo que todo universo é harmonia e número.

No mesmo texto também diz Aristóteles que aos pitagóricos "parecia que toda a natureza se adapta aos números, e que os números são os princípios de toda natureza, entenderam os elementos dos números como constituintes de todas as coisas e que o céu inteiro é harmonia e número".

Para Severino, é "mérito dos pitagóricos o fato de terem elevado a objeto de consideração explícita o sentido da 'unidade', da 'dualidade' e da 'multiplicidade' que, libertas da sua ambientação (e limitação) matemática, constituem determinações universais, sem as quais não é possível uma compreensão filosófica do Todo" (1984, p. 48).

\section{Parmênides}

Parmênides de Eléia, é aquele que podemos considerar o primeiro pensador do Ser, é ele que nos insere no problema que irá ocupar praticamente o centro da filosofia dali em diante. Em meio a um universo em que a realidade está em constante mudança, em devir, opta pelo fundamento permanente, pelo Ser.

Em geral, Parmênides é apresentado estando em oposição, em luta com Heráclito, em posições diametralmente opostas. Enquanto Heráclito teria se pronunciado cabalmente em favor de um ser em constantes e radicais transformações internas, Parmênides teria optado, ao contrário, pelo ser, enquanto uno, imutável e eterno.

Com Parmênides, estamos diante de um pensador do Ser, que luta com as palavras e com a tradição na busca de um fundamento acima da cidade dos homens, não mais ao nível da 
sensibilidade. Precisa desenvolver um método para atingir as coisas, penetrar no coração da realidade toda. Há um ser e um parecer. O parecer é nível da dóxa, o ser da epistéme. É preciso abrir as portas para quem está no desejo de saber, para além da opinião, daquilo que parece. Para ele,

[...] podemos investigar acerca daquilo que existe ou acerca daquilo que não existe. Na verdade, porém, a segunda possibilidade não é legítima uma vez que não se pode pensar sobre, e portanto não se pode investigar, o não existente. De sorte que todo alvo de investigação deve ter existência. Mas tudo que existe deve [...] possuir um corpo de propriedades: deve ser não gerado e imperecível; deve ser contínuo; deve ser inteiramente imutável; e deve ser delimitado e finito, assim como uma esfera. A razão - a capacidade lógica da dedução inelutável - demonstra que a realidade, aquilo que existe, deve necessariamente ser assim: se a percepção sensorial indica um mundo de qualidade diferente, tanto pior para a percepção sensorial (BARNES, 1997, p. 46).

A sensibilidade não é o caminho adequado para tal empreendimento, pois na observação através dos sentidos a realidade é dividida. Importa, na verdade, a unidade dentro da pluralidade, na qual o Ser é o elemento de união. E quem unifica os elementos dispersos é a mente, assim como acontece a unidade entre a mistura de membros do corpo humano, como diz o próprio Parmênides (Fragmento 16). Para ele, assim como no cosmos há mistura e conflito, também no homem acontece o mesmo. O homem se reconhece no funcionamento do cosmos, ou seja, não há diferença entre o homem e o cosmos. Mas a unidade provém do mentar e não da sensibilidade que partilha seu modo de ser com o cosmos. Abdicando da confiança nos sentidos, "presumia que a razão associada ao conhecimento, ou a razão infalível, constituía o critério da verdade" (BARNES, 1997, p. 150).

Com Parmênides podemos dizer que a "cosmologia recebe como que um profundo e benéfico abalo do ponto de vista conceitual, transformando-se, pelo menos em parte, em uma ontologia (teoria do ser)" (REALE, 1990, p. 50).

A própria linguagem, pelo fato de ser movimento, está dentro do âmbito do não-Ser. Mas o Ser não pode ser dito pelo não-Ser ou por aquilo que se movimenta. Se a linguagem nos coloca no mundo da diversidade, é preciso refunda-la, pois o ser, mesmo que se manifeste na physis, ele não é physis.

Mas quem foi Parmênides? Nasceu em Eléia, uma colônia grega no sul da Itália, em torno do ano 540 e morreu por volta de 470 a.C. Dos seus escritos, temos acesso a um poema da pequena extensão, cuja interpretação é bastante difícil, pois num estilo enigmático. Raramente há clareza plena nos seus versos. As diferenças nas interpretações dos fragmentos 
atestam esta dificuldade. A distância temporal interpõe uma carga de conhecimentos e uma tradição muito grande entre a intuição originária do seu pensamento e as interpretações atuais.

Barnes (1997, p. 150) diz que neste poema, após um prólogo alegórico, o corpo principal se divide em duas partes, sendo que a primeira constitui a descrição do Caminho da Verdade, na qual Parmênides apresenta suas concepções pessoais acerca da verdadeira natureza da realidade, e a segunda consiste na apresentação do Caminho da Opinião.

Quem conduz Parmênides no discurso é uma deusa que, de acordo com Reale, parece indicar três caminhos possíveis, sendo o primeiro o da verdade absoluta, o segundo o das opiniões falazes, da falsidade e do erro e o último, da opinião plausível.

No seu poema, no fragmento 2, Parmênides indica aquilo que vale a pena pensar: "primeiro: que é e que não ser não é [...]; o outro: que não é e que não ser é necessário". Segundo a interpretação de Hirschenberger (1965, p. 48), Parmênides está discutindo com Heráclito, no sentido de que não há nenhum devir, que só o ser existe. O devir é o não-ser, porque corre, muda. O ser deverá caracterizar-se por ser estático e ter o sentido de repouso.

No fragmento 3, diz Parmênides que "o mesmo: mentar e ser". Há intérpretes que vêem aí a formulação do princípio da não-contradição, como no caso de Reale (1990, cf. p. 51). Hirschenberger diz que essa afirmação "exprime a teoria cognitiva realista do sadio entendimento humano, consoante ao qual o nosso pensamento é uma reprodução do mundo objetivo e, por aí, idêntico com o ser, de modo que ele espelha o objeto como, em regra, uma cópia reproduz o copiado" (1965, p. 48).

Há ainda uma outra afirmação que merece ser considerada. Diz Parmênides que do ser pode-se afirmar "sendo não gerado, é também imperecível, pois é íntegro, inabalável, ateleológico, nunca jamais foi, nem será, pois é agora, inteiro, completo, uno, constante” (Fragmento 8, 5ss). Ensina, com isso, a unidade do cosmos. Não há diferenças, graduações de intensidade, alterações ou movimentos, devir ou perecer no ser. Não pode começar ou perecer como diz ele um pouco adiante.

Em Parmênides temos, então, o princípio da identidade. Pensava ele que é um absurdo algo ser e não-ser ao mesmo tempo. O movimento existe apenas no mundo sensível e a percepção que advém dos sentidos é ilusória. Concluía pela identidade entre ser e pensar. Para Hirschenberger, "Parmênides conscientemente fixou-se no pensamento como o único caminho para a verdade" (1965, p. 50). Produz uma distinção entre conhecimento sensível e racional que irá perdurar por toda história da filosofia. Todos os racionalismos andarão na 
esteira de Parmênides, buscando um pólo em repouso no fluxo dos fenômenos. Seu pensamento acabou considerando o mundo dos conceitos como o mundo propriamente e em si mesmo, ou seja, transformou o mundo do logos, do discurso, na própria realidade. Esse logos reduziu toda individualidade, multiplicidade e devir em uma uniforme unidade, eterna e imóvel. O mundo sensível somente vive no âmbito da opinião, diferentemente do mundo racional, que lida com a realidade em si mesma.

Mas, para Parmênides, a aparência, de certa forma, faz parte do ser, não como algo complementar, mas como modo próprio do ser se manifestar. A aparência (aparecer) é sair da dimensão do velado, do coberto, é alétheia. A dóxa é a visão formada sem o cuidado necessário na verificação das coisas em si mesmas, ou sem base na própria coisa. É que o ser se oferece, mas também se oculta em seus aspectos, o que pode encobrir o que o ente é na verdade, dissimulando-o. A aparência, o engano, a ilusão, o erro são potências da existência cotidiana. Parmênides busca a verdade, não desconsiderando as opiniões (dóxa), mas pensa que essas devem ser consideradas e pensadas, para que o ser se mostre na aparência contra a aparência.

Verossímil é a aparência do verdadeiro, a face exposta do ser, à medida que ele se torna visível e sonoro, ou seja sensível. No entanto, a opinião é iluminada pela verdade do ser. O engano é uma ausência com aura de presença. A palavra pode ser enganadora e ordenadora ao mesmo tempo. O caos e cosmos se entrelaçam. O importante é que se caminhe, se busque. O errar no caminho é a oportunidade para que a verdade se manifeste. É caminhada do humano para o divino.

Sua palavra é ambígua, exatamente porque sua condição é ambígua. O pensamento é mistura de luz (memória) e trevas (esquecimento). Ao dizer algo, na palavra, está a possibilidade de algo ter sentido, porque, ao nomear, se estabelecem princípios de compreensão que englobarão todas as coisas a algum tipo de conhecimento. E Parmênides critica não as coisas do mundo enquanto tais, mas a forma como os mortais as nomeiam. Como a totalidade dos seres se constitui de dois princípios, a ordenação do mundo deve ser feita a partir deles: Noite, que é obscuridade, que também compõe o humano e é maneira de ser no mundo, e Fogo, que é memória. Segundo Parmênides o erro está em pensar o humano como uma terrível dualidade em que as sementes opostas lutam entre si e não encontram a harmonia na justa medida. Sua natureza é assim harmônica, mas não deixa de ser ambígua. É próprio do humano contar com a obscuridade, para que a luz possa ser percebida como tal.

O dizer humano só ilumina obscurecendo. O humano só é capaz de aspirar à sabedoria 
sem nunca se fundir ao excesso de luminosidade, que ilumina e cega ao mesmo tempo.

O noos é uma visão do espírito que ultrapassa a multiplicidade da percepção sensível com sua função unificadora. Faz a unificação das coisas presentes no ser. E a dóxa para Parmênides é exatamente o esforço de caminhar pela pluralidade do mundo sendo guiado pelo ser já firmemente estabelecido. O noos fundado no ser capta, no momento mesmo em que algo se dá aos sentidos, a unidade do que aparece como múltiplo e descontínuo.

Parmênides busca o ser ao seu derredor, nas coisas presentes. Busca no presente aquilo que antes era ausente. $\mathrm{Na}$ vida de todos os dias, nas coisas presentes que se deve aprender a perceber o ser, deixar-se captar pelo ser.

Resumindo, para ele, é necessário partir em viagem. O mundo deve ser desvelado, desmascarado como cenário onde se dá um jogo de luz e sombra. Parmênides diz o ser e seu discurso visa estabelecê-lo definitivamente, para que o homem possa repousar o coração na Alethéia.

\section{Empédocles}

Natural da colônia dórica de Agrigento, Sicília, fez oposição à oligarquia buscando defender a democracia. Misturava ciência, misticismo e pitagorismo. Sua reflexão pode ser entendida como a primeira síntese da filosofia. Inaugura a concepção de que o princípio de todas as coisas são os quatro elementos: água, terra, ar e fogo, substituindo assim a idéia dos jônios de que havia um único princípio.

Há ainda em Empédocles algumas características da idéia do ser imóvel de Parmênides como também estão presentes as características do ser em eterna transformação, próprio da compreensão de Heráclito. Em seguida a estas concepções vêm as idéias de unidade e de pluralidade dos seres particulares. Como diz Barnes, Empédocles insistia, contrariando os eleáticos, em que

[...] os sentidos, se adequadamente empregados, constituíam rotas para o conhecimento. Concordava com Parmênides em que nada podia realmente passar a existir ou perecer, e concordava com Melisso quanto à impossibilidade da existência de vazios. O universo era pleno de substância eterna. Não obstante, argumentava Empédocles, o movimento era possível e, por conseguinte, também a mudança; pois as substâncias podiam mover-se e misturar-se entre si, promovendo com isso as mudanças por nós observadas (1997, p. 48).

Diante de dificuldade de defender a idéia de um princípio único para toda realidade 
em constante mudança, o caminho passa a ser o pluralismo. Esse pluralismo vem representado na idéia de que o universo é resultado das quatro raízes (água, ar, terra e fogo). Essas raízes permanecem iguais a si mesmas e nenhuma se sobrepõe à outra. A diversidade das coisas, resultante destas quatro raízes, acontece justamente como resultado da mistura delas em diferentes proporções.

Na medida em que nos movemos agora no não-ser, deve-se considerar que também os princípios deste não-ser serão simples: quatro elementos, que se organizam via oposição (forças opostas), que se unem e desunem. São duas as forças primitivas: o amor e o ódio. Pelo amor, muitas coisas se reúnem em uma só; pelo ódio, separam-se em coisas singulares. As partículas das substâncias originárias se segregam e vão formar novas combinações com partículas de outras substâncias. Há uma força que se alia à eternidade da matéria estrutural do mundo. A mudança, o movimento surge, então, pelo fato de que aos elementos originários se alia uma força de atração e repulsão, amor e ódio.

Em relação aos quatro elementos (raízes) diz Hirschenberger que

[...] tudo o que existe com ser vem deles, por mistura e separação. Mas eles, em si mesmos, nas suas qualidades, são algo de último: nem começaram a existir, nem deixarão de ser; apenas partículas deles se segregam e vão formar novas combinações com partículas de outras raízes. O que os homens chamam nascer e morrer, não passa de combinação seguida de separação (1965, p. 55).

Desse modo, todas as coisas "surgem e não lhes é estável a vida. Embora as transformações jamais se extingam, subsistem sempre imóveis em cada ciclo" (Empédocles, § 26). Mais tarde no texto diz ele que "desses elementos formaram-se harmonizadas todas as coisas, por eles os homens pensam, gozam e sofrem" (\$107).

Kirk afirma que "a idéia crucial da reconciliação é que, enquanto o processo dual, descrito nos versos $1-5$, se repete incessantemente, as coisas nele envolvidas são por assim dizer imutáveis. Uma unidade formar-se-á sempre de uma pluralidade e vice-versa; e será sempre a mesma unidade e a mesma pluralidade" (1994, p. 301).

O que acontece é que agora a soberania da razão já não tem mais lugar. Pode-se dizer que o conhecimento se democratiza. A apreensão da realidade se faz via diversos elementos e não somente pela razão. O homem participa radicalmente da realidade do mundo e isto tem implicações na percepção: “com terra percebemos terra, com água percebemos água, com éter percebemos o divino éter, com fogo percebemos o fogo devastador, com afeto, afeto; com ódio o lúgubre ódio" (EMPÉDOCLES, 109). Ou seja, nós sempre conhecemos o semelhante 
pelo semelhante.

Dá-se, com Empédocles uma vinculação radical com o universo, com o não-ser. A totalidade foge da observação. Podemos somente pensar dentro da morte, como mortais, ou seja, retornamos ao campo da observação, em que a pele estabelece comunicação com o mundo. O princípio, o fundamento de tudo é imanente. Podemos também dizer que o homem pensa sua condição de morte, vinculado à vida. É o não-ser que é a existência, pois sou verdadeiro quando respiro, morro, choro. De modo que a verdade não é intelectual.

Como diz o próprio Empédocles (Fragmento 02), cada um "topa o que topa", mas presumimos "abarcar a totalidade". Na verdade "porção minúscula da vida observamos no decurso da existência" e "conhecerás só o que à inteligência mortal é dado saber". Todas essas expressões mostram o retorno à sensibilidade, à observação, à mortalidade, do encontro com as partes e nunca com a totalidade, retorno do imortal ao mortal.

Para ele, o pensamento é uma construção, uma re-elaboração, um processo de queimar os conteúdos. Não há mais uma deusa, como no caso de Parmênides, que revela e conduz à verdade, mas uma combustão em que o próprio discurso ilumina a mente, como material a ser queimado, re-elaborado, em que acontece a libertação do peso da tradição. A musa somente permite esse processo. Se o carro de Parmênides é guiado pelas Ilíades, o carro de Empédocles é submisso ao pensador efêmero.

Temos, assim, uma apologia dos sentidos, sem privilégio de algum deles em especial. E, quanto ao discurso, por mais nobre que seja sua origem, ele deve ser sempre examinado antes de sua aceitação. Também o discurso não é estável. O perecível atinge o discurso. Tudo aquilo que tem pretensão de perenidade é destruído.

Pode-se afirmar que a filosofia de Empédocles representa, de certa forma, a conciliação entre Parmênides e Heráclito, daí a possibilidade de perceber nela certo ecletismo. Em função dos extremos construídos por Parmênides e Heráclito, surge uma tentativa de conciliação. Além disso, é possível também dizer da presença de uma influência de Parmênides no filósofo em questão, sobretudo no que se refere à concepção do Ser que seria entendido como única realidade. O ser de Empédocles é incriado, indestrutível, indivisível e idêntico a si mesmo, daí a compreensão do não surgimento da pluralidade.

\section{Górgias}


Górgias nasceu em 487 e morreu em 380 e faz parte de um grupo de pensadores chamados de sofistas. Diante dos problemas e das tentativas efetuadas pelos filósofos anteriores, diante das antinomias da razão e da experiência, os sofistas trazem a questão da capacidade do homem para alcançar a verdade para o primeiro plano. Com eles, a filosofia

[...] concentra sua atenção precisamente sobre o homem que conhece e sobre o valor do conhecimento: pode o homem alcançar um saber necessário, absoluto e irrefutável se, no próprio seio da verdade, se acendeu uma discordância radical entre os dois momentos fundamentais da própria verdade (a experiência e a razão)? E como se pode esperar conciliar esta discordância se as forças em luta são antitéticas e, portanto, por definição, inconciliáveis? (SEVERINO, 1984, p. 67).

Analisando o pensamento precedente, o que se encontra são infinitas discordâncias, disparidade de opiniões. E Górgias coloca em evidência o caráter contraditório dos resultados alcançados pelo pensamento humano. Diz o fragmento intitulado Sobre o Não-Ser, de um autor anônimo, que "Sintetizando declarações de outros, Górgias afirma: não é" (§ 2). Enquanto alguns afirmam a unidade, outros a negam e afirmam a pluralidade e o mesmo acontece com a opinião em torno do gerado e não-gerado. Dessa forma, diante das oposições, nada é. Se algo fosse, seria uma ou outra posição. Górgias busca mostrar então que não é nem um nem outro. Nada é. Diante das contradições das teses sobra nada. "O que é ambos não é um nem outro" (Sobre o não-ser, § 4).

Górgias afirma também que o não-ser em nada é inferior ao ser. Se Parmênides diz que o ser não tem origem, não se movimenta (de ser a ser) e não tem fim, para Górgias, o nãoser é depositário dos mesmos atributos, ou seja, o não ser também não tem origem, não se movimenta e não tem fim. Logo, ser é igual a não-ser. Ser e não-ser tem os mesmos predicados. Com isso, chega a afirmar a reversibilidade entre ser e não-ser. Ser e não-ser é e não-é.

A verdade, portanto, é indemonstrável, e "mesmo que as coisas sejam, elas nos são incognoscíveis" (Sobre o não-ser, 9). A coisa é somente no discurso. Se fosse, por acaso, cognoscível, "como poderia alguém manifestá-la a outro? O que alguém viu, assevera, com que palavra poderia dizê-lo?" (Sobre o Não-ser, §10). E mais adiante diz o autor: "se conhecemos e reconhecemos por palavras, como terá o ouvinte em mente a mesma coisa?" (§11). Pois parece que

[...] nem o mesmo sente coisas semelhantes ao mesmo, no mesmo instante, mas diversas ao ouvido e à visão, e diferentes do passado e do presente. De sorte que dificilmente alguém perceberia algo inteiramente igual a outro. Assim - a unidade não é, o conhecido é - ninguém exporá o mesmo a outro, já que as coisas não são palavras, e porque ninguém tem na mente o mesmo 
que o outro (Sobre o não-ser, §11).

É necessário notar, contudo, que isso acontece somente no plano do discurso. 'Nada é' somente discursivamente. É um pensamento sem recurso à sensibilidade. Ele inclusive nega o princípio da não-contradição. Para Górgias as palavras têm um poder mágico, persuasivo: “a persuasão, projetada pela palavra, molda a psique a seu bel-prazer" (O elogio de Helena, §13). Assim, "uns discursos agradam, outros alarmam, outros armam os ouvintes de coragem, outros, com persuasão maléfica, envenenam a psique e enganam” (§14).

A verdade somente adorna o discurso. A verdade é um discurso eficaz, que não pode pretender validade universal, visto que está no movimento, no não-ser. Não há como fazer diferenciação entre o verdadeiro e o falso. O que conta, portanto, é aquilo que convence, que é eficaz.

Górgias está no âmbito do cosmético, do não-ser. Para ele não há essência. Há somente aquilo que (a)parece. O restante não se atinge. Não há uma instância para fundamentar a verdade, pois o fundamento é o próprio discurso em movimento, que tem poder maior ou menor de convencimento, que se torna eficaz ou não. A retórica é, portanto, 'a' ciência. Pois, "se não existe uma verdade absoluta e tudo é falso, a palavra adquire então uma autonomia própria, quase ilimitada, porque desligada dos vínculos do ser” (REALE, 1990, p. 79).

Diante da impossibilidade de alcançar uma verdade absoluta, Górgias poderia optar pelo caminho da opinião (dóxa). Não o fez, pois negou também a opinião. De acordo com Reale, ele trilha um terceiro caminho, "o da razão que se limita a iluminar, circunstâncias e situações da vida dos homens e das cidades" (1990, p. 79).

\section{Conclusão}

No decorrer deste breve trabalho quisemos enfatizar a importância do pensamento originário em função do seu vigor que continua a imperar inclusive na atualidade. Nele encontramos os germes das grandes questões físicas e metafísicas com que nos debatemos ao longo da existência da filosofia e inclusive das outras áreas de conhecimento.

Eles, no dizer de Barnes,

[...] descobriram aquela maneira especial de olhar para o mundo que é a maneira científica ou racional. Viam o mundo como algo ordenado e 
inteligível, cuja história obedecia a um desenvolvimento explicável, sendo suas diferentes partes organizadas em algum sistema compreensivel. $O$ mundo não era uma reunião aleatória de partes, tampouco sua história uma série arbitrária de eventos (1997, p. 18).

Eles foram os primeiros a buscar explicar o universo e a experiência humana a partir do esforço da própria razão humana. Mesmo estabelecendo princípios, fundamentos externos, divinos, metafísicos, é a razão humana que está trabalhando, observando e construindo uma explicação. Há uma ordem intrínseca no mundo que é suficiente para poder explicar-lhe a existência, a estrutura e o movimento que nele se opera.

As explicações dos pré-socráticos têm algumas características comuns: são internas, pois explicam o universo a partir de dentro, a partir das próprias características que o constituem, sem apelar para intervenções arbitrárias e, segundo, são sistemáticas, pois explicam a soma total dos eventos naturais empregando os mesmos termos e os mesmos métodos, construindo princípios gerais que se aplicam a tudo. São também econômicas, no sentido de que empregam poucos termos, exigem poucas operações e assumem poucas incógnitas, ou seja, a multiplicidade deve ser reduzida a uma ordem simples que permita a inteligibilidade.

Nos parece importante frisar também que, de acordo com o que pudemos notar, esse pensamento mantém um grande vigor, no sentido de que está a caminho, não está comprometido com mestres, tradições. Faz exatamente o contrário: liberta o discurso para o exercício democrático. Um pensador não está comprometido com as conclusões do outro, mas está comprometido com a resolução dos problemas que surgem e que lhe pedem uma explicação.

Passando pelos pensadores que consideram a sensibilidade como o caminho adequado para se conhecer a realidade até aqueles em que o amor pela argumentação é mais evidente e mais pronunciado, mostramos brevemente alguns aspectos da nossa história de pensamento. Vimos como em alguns a argumentação ganha o lugar de único veículo da verdade, enquanto a percepção é tida como ilusória. Em outros acontece exatamente o contrário. Não há dúvidas, no entanto, que o que produziram foi um pensamento vivo e que continua atuante em todos os que vieram depois deles, inclusive atualmente.

Isso mostra que a filosofia não é uma teoria distante da vida. Ela é uma forma de vida. Não é apenas algo que se contempla, mas algo que se vive e que fala do sentido da nossa existência. Ela tem tudo a ver com a aventura da existência concreta, que busca explicações para o ser e existir. Apesar das maneiras particulares de conceber e exercer a atividade 
filosófica, todos os pré-socráticos produzem algo comum chamado de Filosofia.

\section{Referências}

ARISTÓTELES. Metafísica. Vol II. São Paulo: Edições Loyola, 2002.

KIRK, G. S, RAVEN, J. e SCHOFIELD, M. Os filósofos pré-socráticos. Trad. Carlos Alberto L. Fonseca. Lisboa: Gulbenkian, 1994.

REALE, ANTISERI. História da filosofia. Volume I. São Paulo: Paulinas, 1990.

BARNES, J. Filósofos pré-socráticos. São Paulo: Martins Fontes, 1997.

SEVERINO, Emanuele. A filosofia antiga. Lisboa: Edições 70, 1984.

CARNEIRO LEÃO. Aprendendo a pensar. Petrópolis: Vozes: 1990.

HIRSCHENBERGER, JOHANNES. História da filosofia na Antiguiidade. São Paulo: Editora Herder, 1965.

SCHÜLLER, Donaldo. Fragmentos dos Pré-Socráticos (Pitágoras, Parmênides, Empédocles e Górgias). Tradução para uso interno. 